\title{
PEMBUATAN DAN IMPLEMENTASI WEBSITE DESA PANDOWOHARJO
}

\author{
Tri Sutrisno $^{1}$, Dedi Trisnawarman ${ }^{2}$ \\ ${ }^{1}$ Program Studi Teknik Informatika, Universitas Tarumanagara \\ Email: tris@fti.untar.ac.id \\ ${ }^{2}$ Program Studi Sistem Informasi, Universitas Tarumanagara \\ Email: dedit@fti.untar.ac.id
}

\begin{abstract}
ABSTRAK
Diberlakukannya Undang-undang nomor 6 tahun 2014 tentang desa memberikan peluang besar bagi setiap desa untuk maju dan bersaing menghadapi tantangan global, salah satu peluang yang dapat digunakan adalah memanfaatkan teknologi informasi. Dibutuhkan media yang berbasis teknologi informasi agar dapat menjadi pendukung dalam penyampaian informasi dan sarana promosi desa. Media yang tepat untuk mendukung maksud tersebut adalah wesite desa. Kegiatan Pengabdian kepada Massyarakat ini bertujuan membangun dan menerapkan website desa. Metode pelaksanaan adalah metode pengembangan perangkat lunak yaitu metode prototyping yang melibatkan pengguna secara aktif. Pelaksanaan kegiatan pengabdian kepada masyarakat ini menghasilkan sebuah produk website yang dihosting dengan alamat url: http://www.pandowoharjo.web.id. Penerapan website ini diharapkan dapat meningkatkan arus informasi yang dapat disampaikan secara efektif kepada masyarakat desa tentang kegiatan pemerintahan desa, layanan masyarakat, dan dapat digunakan sebagai sarana promosi bagi desa wisata budaya Pandowoharjo.
\end{abstract}

Kata kunci: website, desa, pengembangan, penerapan

\section{PENDAHULUAN}

Berdasarkan data statistik pertanggal 30 Juni 2016, lebih dari 50,1\% penduduk dunia telah menggunakan internet dan pengguna internet di Indonesia mencapai lebih dari 132,700,000 orang (www.internetworldstats.com), atau 51,4\% dari total jumlah penduduk Indonesia. Diperkirakan penggunaan internet akan makin meluas dengan cepat seiring dengan perkembangan infrastruktur dan ketersediaan teknologi informasi yang makin terjangkau

Internet merupakan salah satu media informasi yang paling efektif untuk penyebaran informasi. Inpres tahun 2003 menginstruksikan kepada instansi-instansi pemerintah untuk mengimplementasikan system egovernment bagi pelayanan masyarakat. Hadirnya internet memudahkan ruang dan jarak dalam berkomunikasi. Seperti yang digambarkan oleh McLuhan dalam Understanding Media (2001) sebagai kampung global (global village), dimana masyarakat berinteraksi dan dibentuk oleh teknologi elektronik di dunia semakin mengerut. Internet dapat digunakan untuk pemecahan masalah yang melibatkan komunitas atau masyarakat

Indonesia telah mengalami pengglobalan dalam bidang informasi, sejak kemunculan internet pada pertengahan 90-an. Melalui internet dan televisi membuat masyarakat Aceh dapat melihat apa yang sedang terjadi di Surabaya, begitu juga penduduk Jakarta yang dapat melihat apa yang sedang terjadi di Indonesia bagian Timur. Melalui internet, masyarakat antar satu kelompok dapat berhubungan dengan kelompok lain di dunia maya, saling berbagi informasi dan berkomunikasi. 


\subsection{Permasalahan Mitra}

Dengan diberlakukannya Undang-undang nomor 6 tahun 2014 tentang Desa maka menjadi peluang yang sangat besar bagi setiap desa yang ada di Indonesia untuk bisa mengembangkan setiap potensi yang dimilikinya secara mandiri sesuai kebutuhan masing-masing dalam rangka mewujuskan kesejahteraan masyarakat.

Pengaturan Desa antara lain bertujuan mendorong prakarsa, gerakan, dan partisipasi masyarakat Desa untuk pengembangan potensi dan Aset Desa guna kesejahteraan bersama; serta. memajukan perekonomian masyarakat Desa serta mengatasi kesenjangan pembangunan nasional; (UU nomor 6 th 2014 pasal 4). Namun saat ini masih sangat sedikit desa yang mampu mengembangkan potensinya. Hal ini disebabkan selama ini desa lebih banyak diposisikan sebagai obyek pembangunan sehingga sangat menggantungkan diri pada bantuan pemerintah pusat. Rendahnya kreatifitas sumber daya manusia di desa sebagai akibat dari sistem pembangunan yang bersifat sentralistik pada masa lalu mengakibatkan banyak potensi dibiarkan terbengkalai tidak dikembangkan untuk sumber kemakmuran masyarakat.

\subsection{Solusi Mitra}

Solusi yang ditawarkan adalah dari sisi pengetahuan teknologi informasi sesuai dengan bidang pengetahuan dan pengalaman tim pengusul. Berdasarkan pengetahuan dan pengalaman dalam bidang teknologi informasi, maka masalah yang dihadapi adalah masalah yang berkaitan dengan masalah penggalian dan penyebaran informasi diharapkan dapat diatasi. Masalah komunikasi adalah membangun dan mengimplementasikan Portal Website Desa, yang dapat digunakan untuk sarana informasi, komunikasi dan kolaborasi dalam permasalahan pembangunan Desa. Web desa juga dapat digunakan sebagai sarana promosi yang dapat medukung tujuan pembangunan desa.

Solusi yang ditawarkan diharapkan akan memberi manfaat sebagai berikut:

- Dapat digunakan sebagai sarana memperkenalkan profil Desa sehingga dapat sebagai sarana promosi memperkenalkan potensi Desa

- Penyebaran informasi mengenai permasalahan yang cepat, tanpa dibatasi tempat dan waktu

- Memfasilitasi usulan warga Desa

- Sebagai sarana komunikasi dan koordinasi warga Desa

- Mempercepat proses layanan masyarakat

- Pengarsipan informasi yang efisien

\subsection{Target Luaran}

Jenis luaran yang dihasilkan yaitu berupa produk website dengan fitur-fitur sebagai berikut:

- Beranda (Home)

- Profil Desa

- Wilayah Desa

- Pemerintahan Desa

- Badan Permusyawarahan Desa

- Profil Desa Budaya

- Potensi 
- Kerajinan

- Wisata

- Kuliner

- Budaya

- Lembaga Kemasyarakatan Desa

- $\mathrm{RT} \& \mathrm{RW}$

- PKK

- Karang Taruna

- LPMD

- Adminstrasi Padukuhan

- Data Desa

- Data Wilayah Adminstratif

- Data Pendidikan Dalam KK

- Data Pendidikan Ditempuh

- Data Pekerjaan

- Data Agama

- Data Jenis Kelamin

- Data Golongan Darah

- Data Kelompok Umur

- Data Warga Negara

- Data Penerima KIP

- Data KK Miskin

- Data Ekonomi

- Layanan

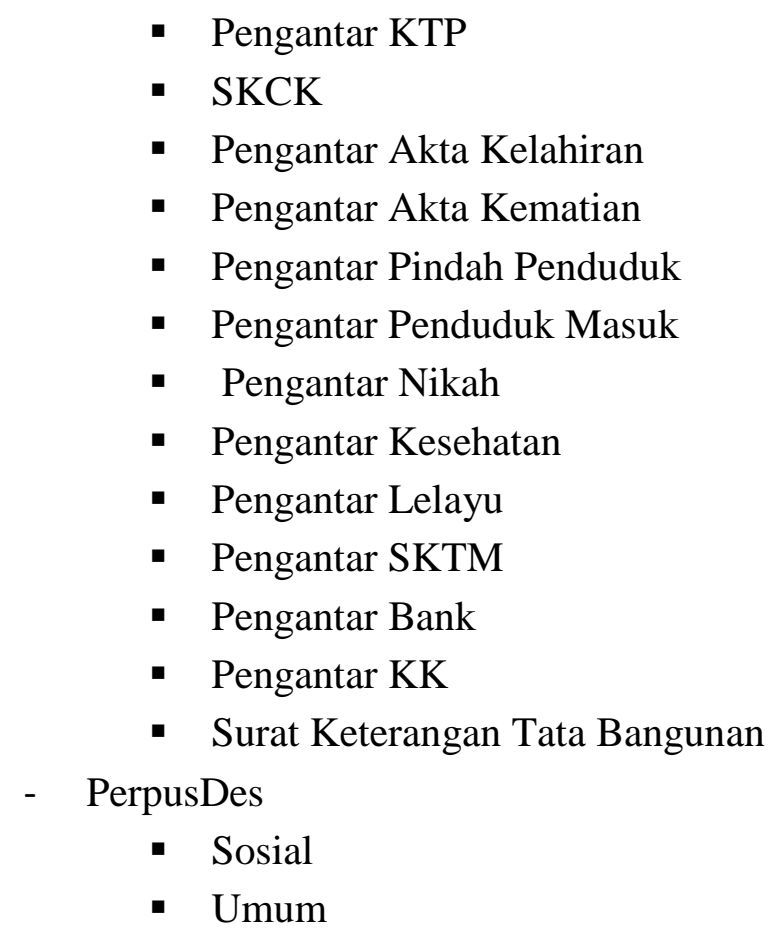




\author{
- Sains \\ - Teknologi \\ - Satra \\ - Filsafat \\ - Bahasa \\ - Agama \\ - Sejarah \& Geografi \\ - Foto Galery \\ - Kontak
}

Website yang dikembangkan dapat digunakan dalam penyebaran informasi dan membantu pengarsipan berita atau kegiatan instansi.

\title{
2. METODE PELAKSANAAN PKM
}

Kegiatan utama yang dilakukan adalah mengembangkan website dengan beberapa fungsi sebagai penyimpan data. Selanjutnya, untuk perancangan sistem perangkat lunaknya menggunakan metode Rapid Application Development (RAD) (Setiawan, 2011). Metode RAD memiliki fasefase melakukan perencanaan syarat-syarat kebutuhan sistem, melibatkan pengguna untuk merancang sistem dan membangun sistem (kegiatan ini dilakukan secara berulang-ulang hingga mencapai kesepakatan bersama), dan terakhir tahap implementasi yang diikuti dengan tahap pelatihan bagi pengguna (Kosasi, 2015), seperti yang ditunjukan pada gambar berikut.

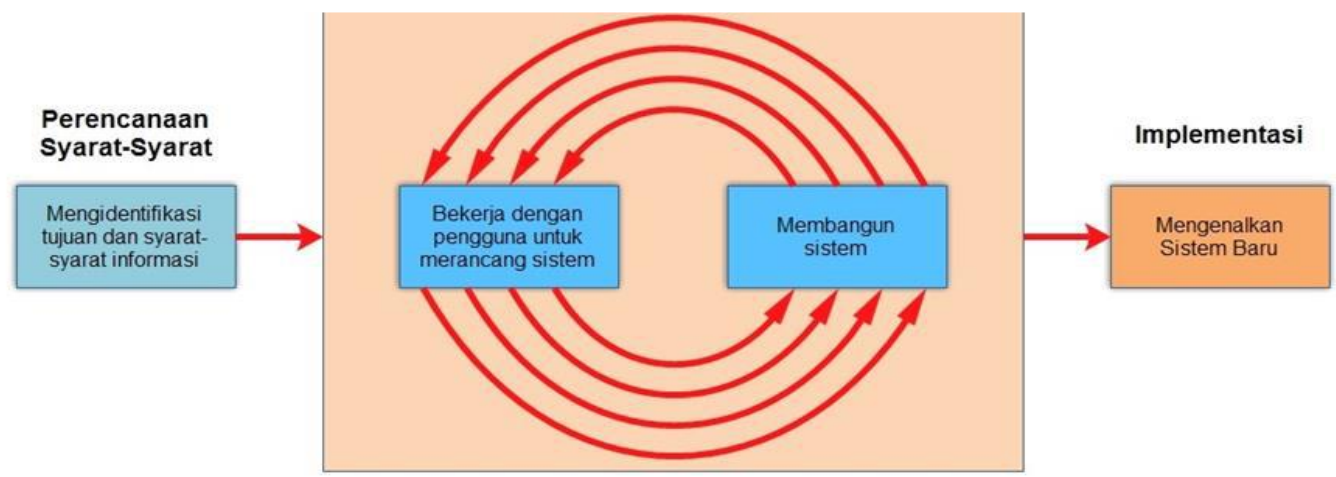

Gambar 1. Metode RAD (Rapid Application Development) (Kosasi S, 2015)

Metode RAD memilki tahapan sebagai berikut (Setiawan, 2011)

- Bussiness modeling

Pada tahapan business process, pekerjaan yang dilakukan adalah analisis proses bisnis.

Dalam proses ini hasil yang diharapkan adalah pengumpulan kebutuhan(requirement), yaitu user requirement dan system requirement.

- Data modeling

Pada tahapan ini pekerjaan yang dilakukan adalah mendefinisikan dari fase business modeling disaring ke dalam serangkaian objek data yang dibutuhkan untuk menopang 
bisnis tersebut. Pemodelan data yang dibuat menggunakan tools diagram unified modeling languange (UML)

- Process modeling

Pada tahapan process modeling pekerjaan yang dilakukan adalah membuat alur proses dari perangkat lunak peduduk miskin. Alur proses yang dibuat tersebut mencakup menambah, memodifikasi, menghapus, atau mendapatkan kembali sebuah objek data

- Application generation

Tahapan application generation pekerjaan yang dilakukan adalah melakukan pengkodean atau implementasi dari process modeling dan data modeling.

- Testing and turnover

Pada tahapan testing, pekerjaan yang dilakukan adalah melakukan pengujian perangkat lunak yang telah dibuat. Pengujian tersebut dilakukan pada perangkat lunak yang memiliki komponen baru dan secara menyeluruh.

Software utama dalam penelitian ini adalah PHP dan MySQL dengan CMS Joomla untuk pembuatan desain web.

\section{HASIL DAN PEMBAHASAN}

Hasil dan luaran yang dicapai dalam kegiatan penelitian ini dibagi menjadi dua, yaitu hasil perancangan website dengan luaran berupa produk website, dan hasil implementasi produk yang dirancang berupa website yang sudah dihosting dan dapat diakses oleh masyarakat desa.

\subsection{Rancangan website Desa}

Hasil rancangan website Desa Pandowoharjo dapat dilihat dapat dilihat pada url : http://pandowoharjo.web.id. Tampilan homepage-nya seperti pada Gambar 2. 


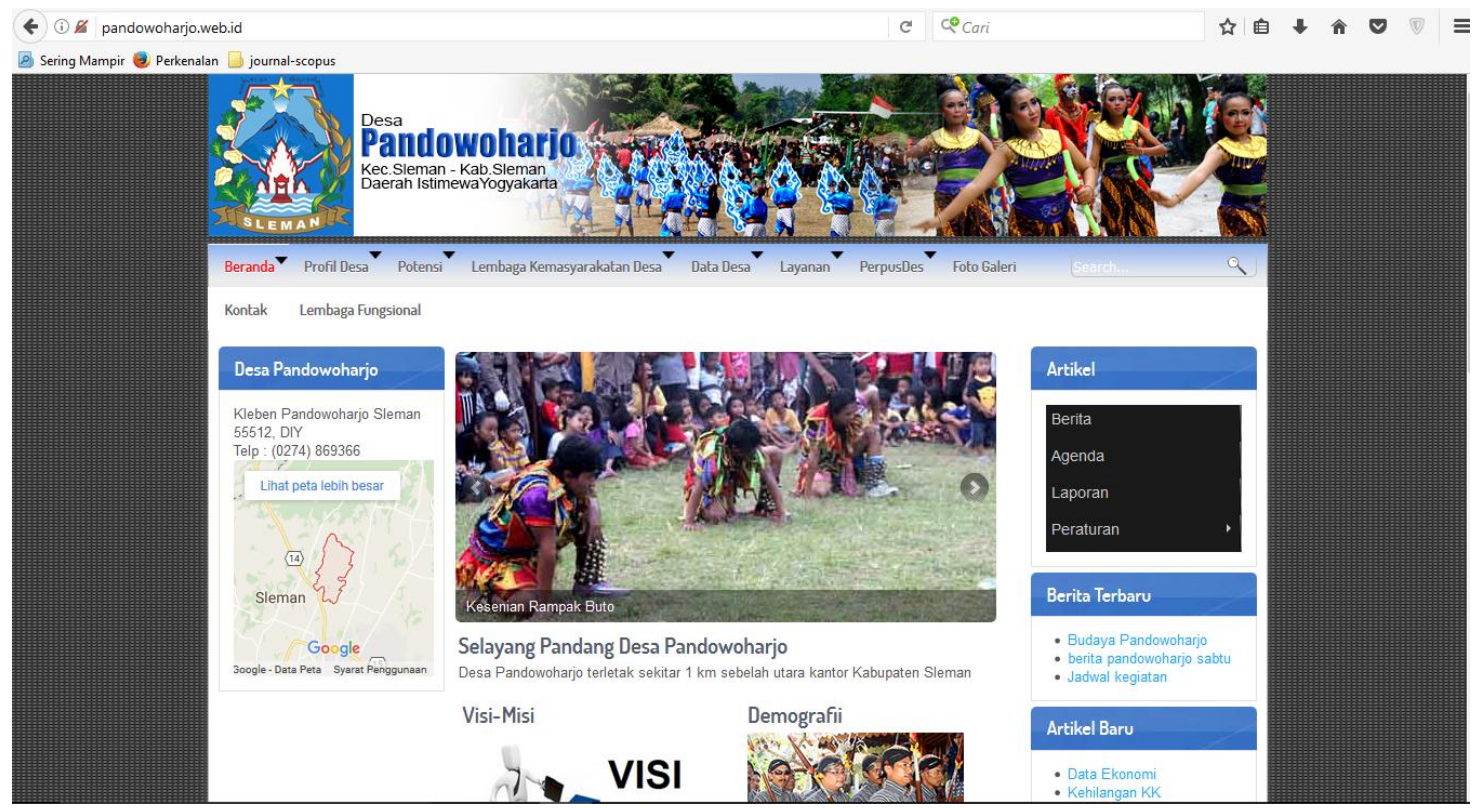

Gambar 2. Homepage (halaman depan) website Desa Pandowoharjo

Dari halaman depan website, kita tinggal menambahkan huruf “/” (garis miring) dan kata “administrator", seperti yang ditunjukkan oleh Gambar 3.

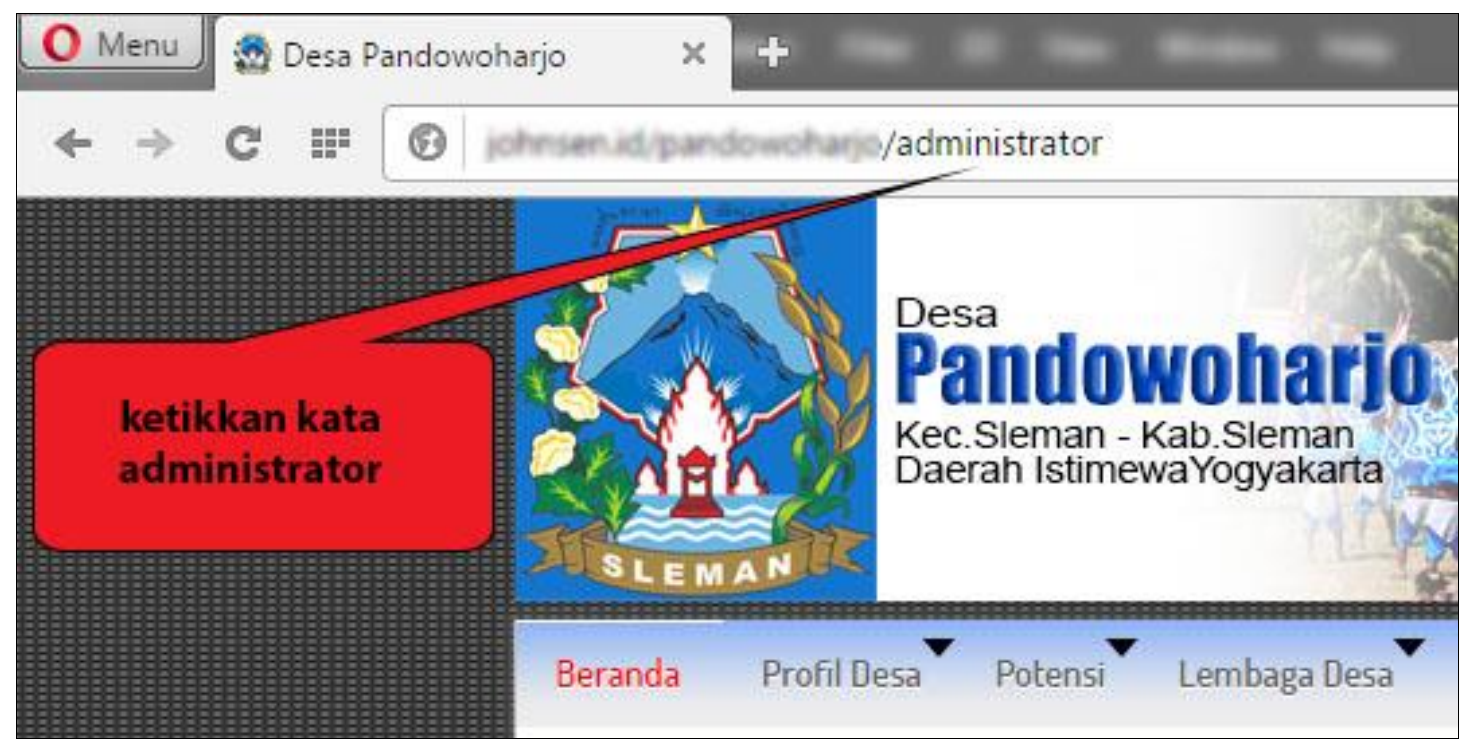

Gambar 3. Tambahkan "/administrator " untuk mengakses back-end website

Pada website Desa Pandowoharjo ada dua kelompok menu. Yang pertama adalah Menu Utama yang berada pada bagian atas website. Yang kedua adalah Menu di bagian kanan website (Gambar 3). Untuk menampilkan artikel yang sudah dibuat sebelumnya, maka akan dibuatkan menu pada salah satu menu tersebut atau bahkan bisa dibuatkan pada kedua menu tersebut. 


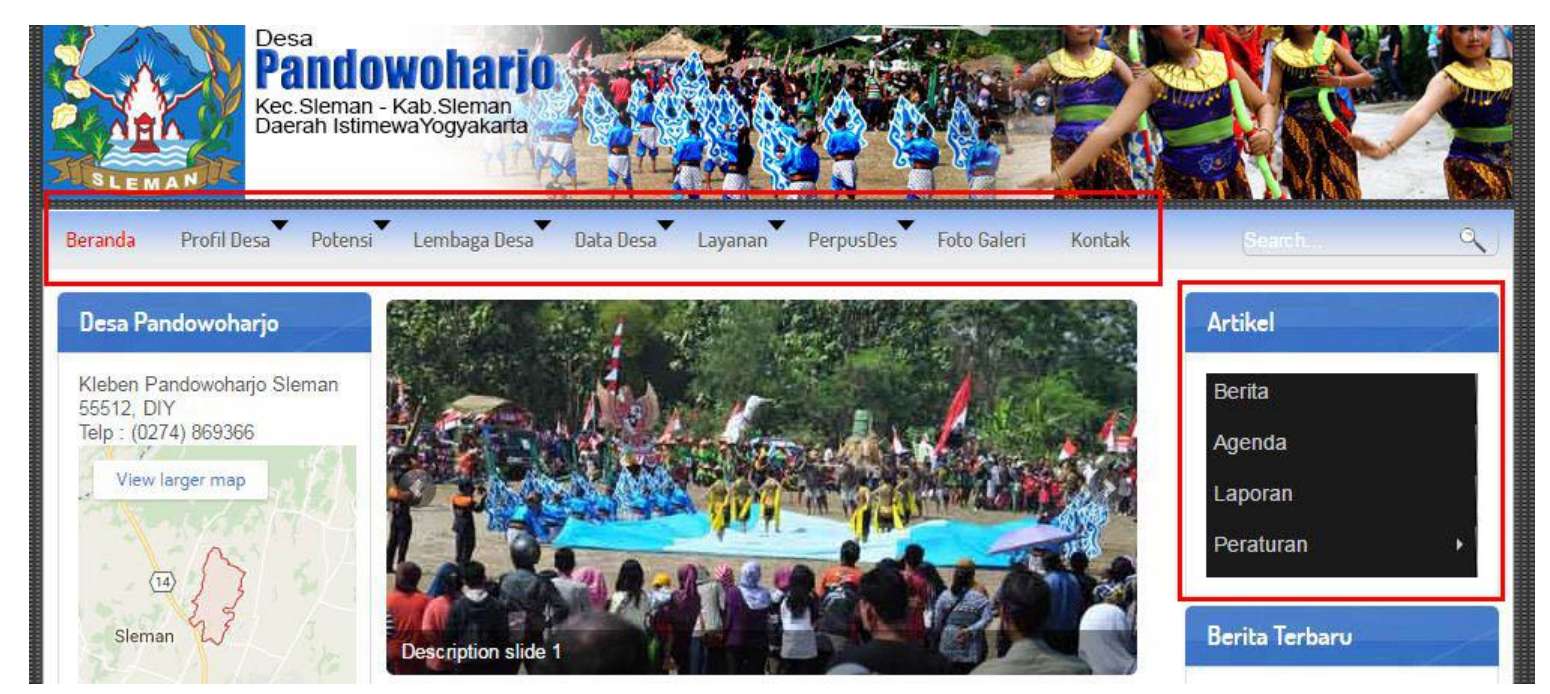

Gambar 4. Menu utama navigasi pada bagian atas dan pada bagian kanan website

Untuk membuat sebuah menu baru, misalnya pada menu utama (menu navigasi bagian atas), maka klik Menus | Main Menus | Add Menu Item. Untuk membuat menu di bagian kanan dapat klik Menus | Artikel | Add Menu Item, seperti terlihat pada gambar 5.

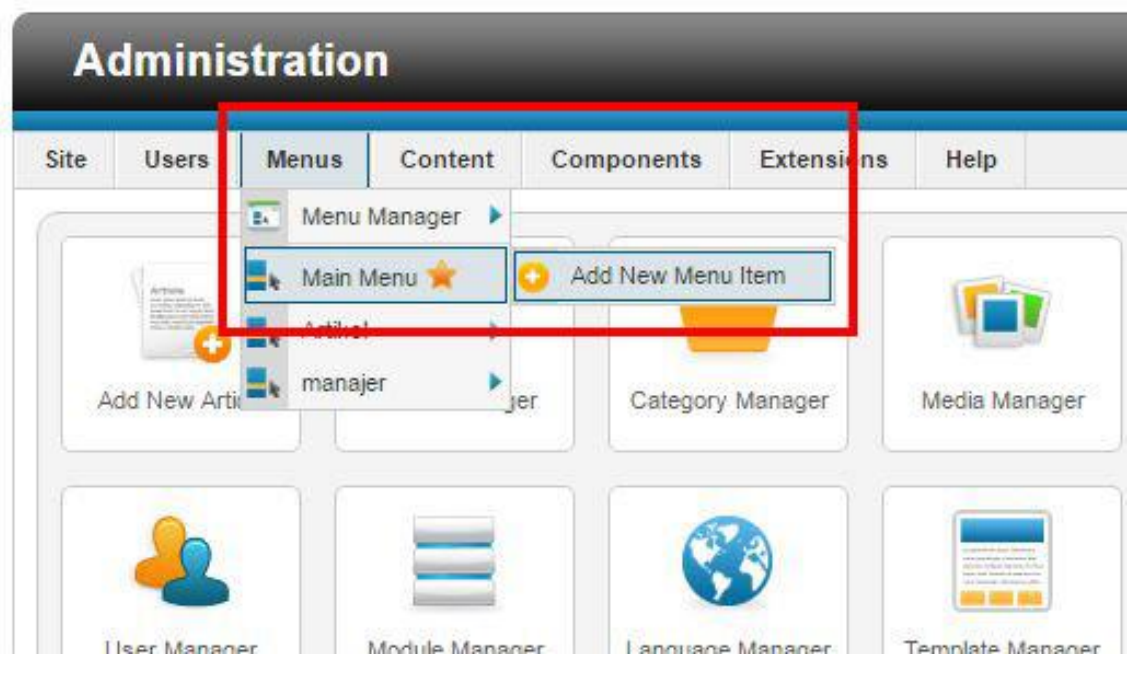

Gambar 5. Membuat menu baru pada Menu Utama.

\subsection{Pelatihan Pengguna}

Website yang sudah dihosting dan dapat diakses oleh masyarakat desa, butuh pemeliharaan mantenance, agar informasi yang ditampilkan dapat selalu terbahrui. Untuk itu perlu dilakukan pelatihan bagi pengguna yang bertindak sebagai administrator dan yang bertanggung jawab terhadap pemeliharaan web. Pelatihan yang diselenggarakan dalam kegiatan pengabdian kepada masyarakat ini dilakukan pada tahap kedua, yaitu semester berikutnya setelah pembuatan dan hosting web.

Pelatihan diikuti kepala desa sebagai penanggung jawab dan sekretaris desa sebagai ketua pelaksana web desa, seluruh kepada dusun (dukuh) atau yang mewakilinya, pamong desa dan 
operator web yang ditugaskan secara khusus untuk menangani website desa. Pelatihan dilakukan selama satu hari penuh yaitu mulai jam 08.00 sampai dengan jam 16.00, bertempat di balai desa Pandowoharjo. Kegiatan pelatihan dapat dilihat seperti pada Gambar 6, 7, 8.

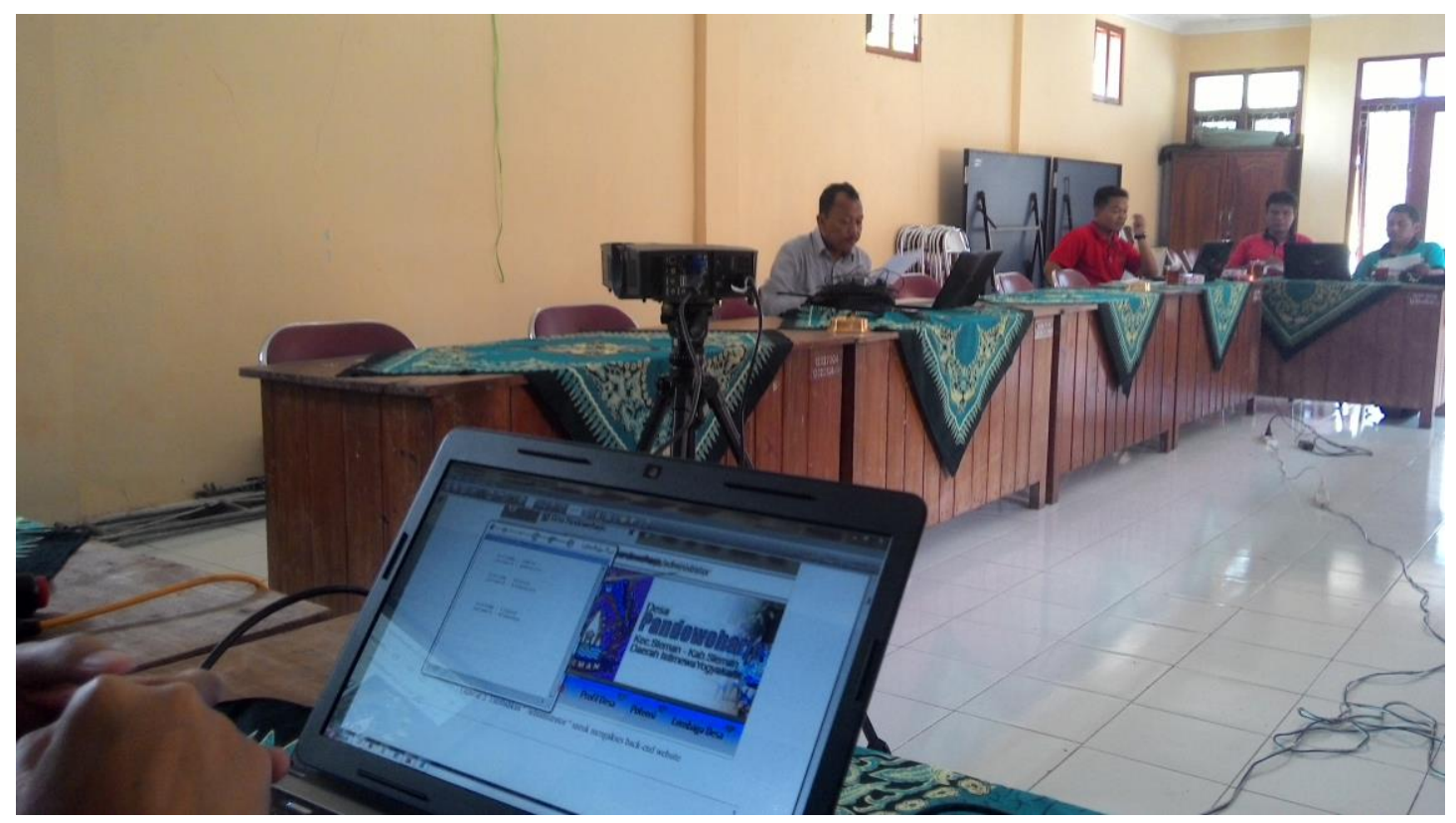

Gambar 6. Pelatihan Website Desa Pandowoharjo

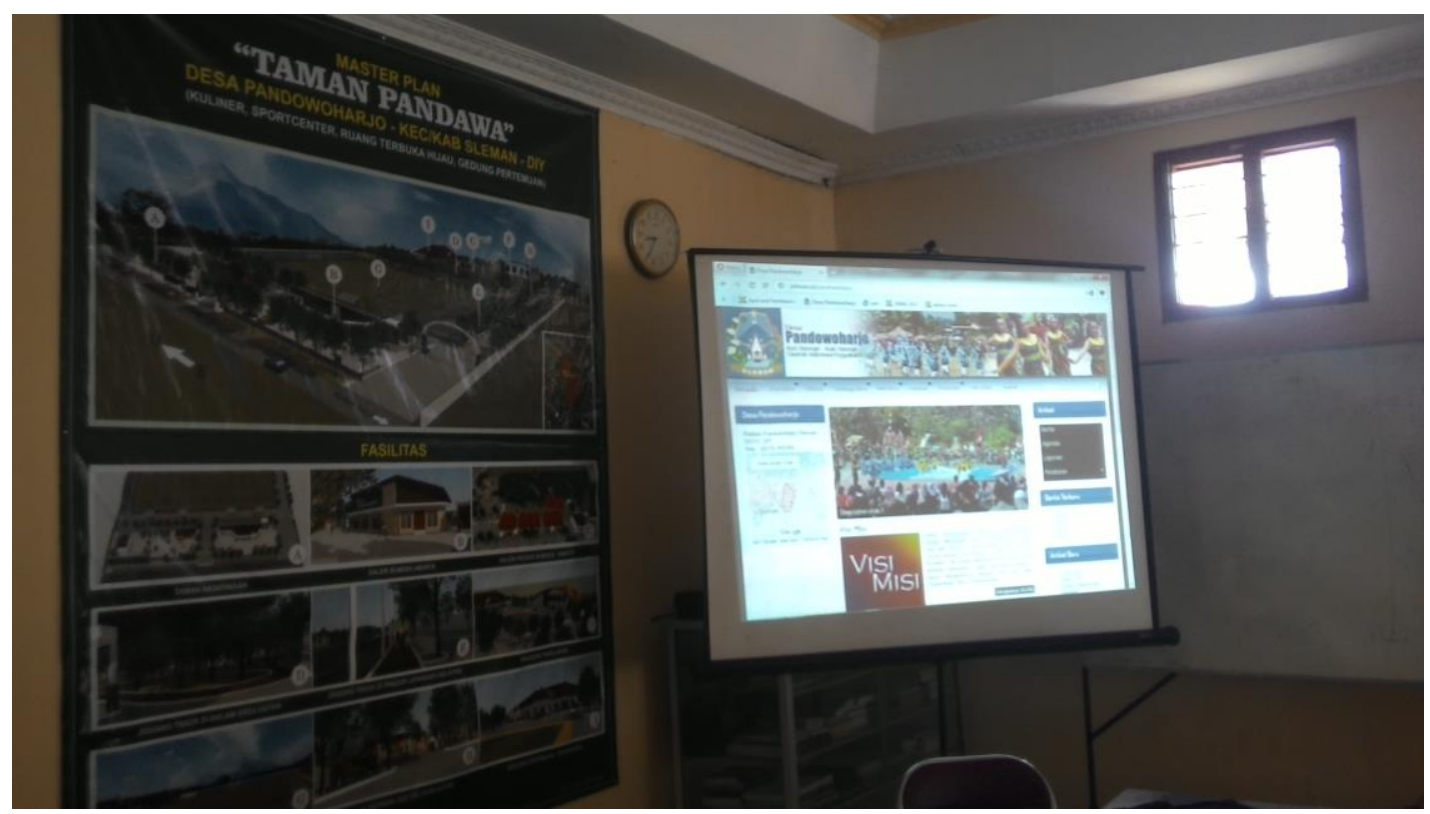

Gambar 7. Pelatihan Website Desa Pandowoharjo 


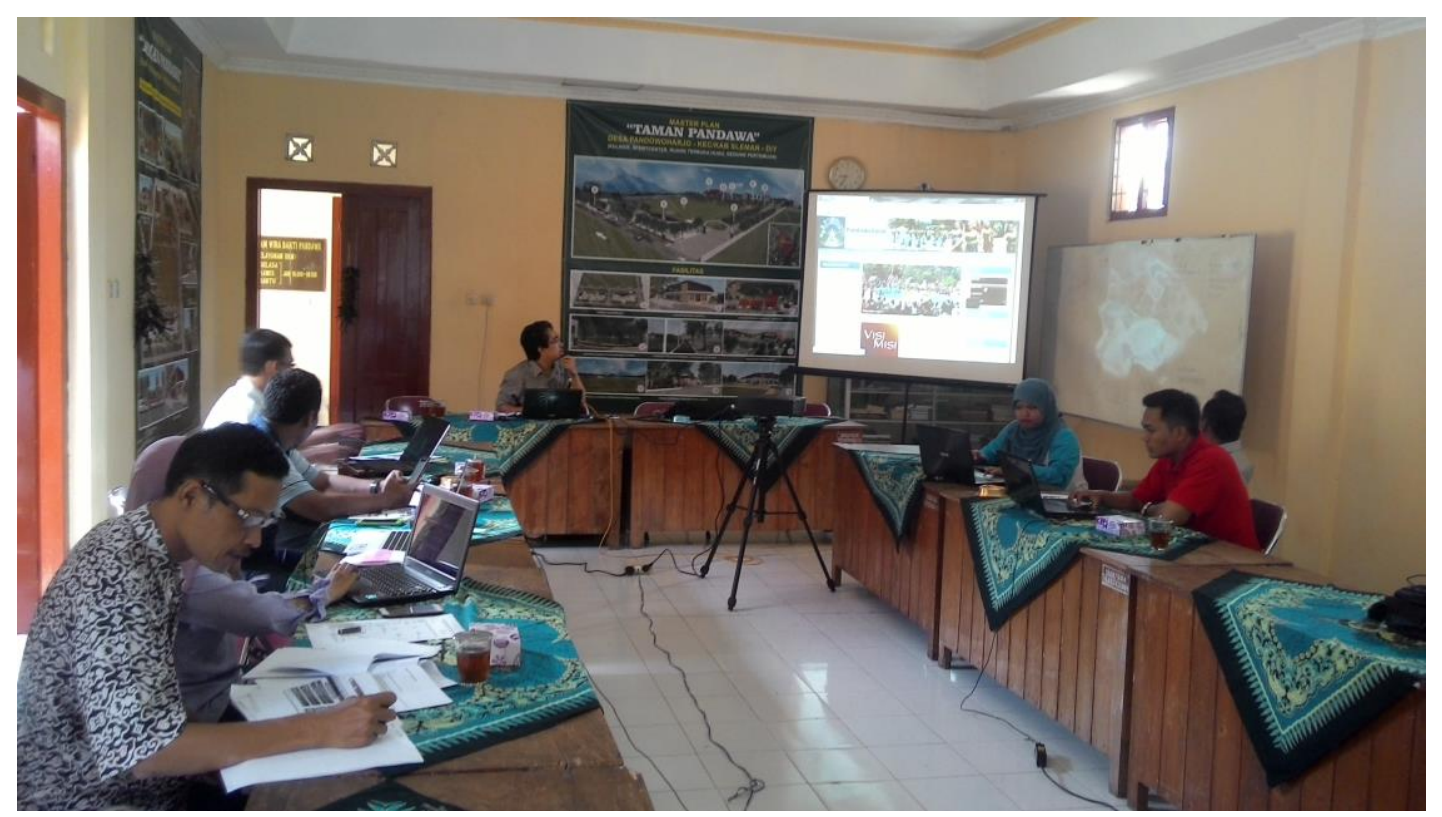

Gambar 8. Pelatihan Website Desa Pandowoharjo

\section{KESIMPULAN DAN SARAN}

Dari hasil kegiatan pengabdian kepada masyarakat yang telah dilakukan, dapat disimpulkan bahwa:

- Masyarakat dan Pemerintahan Desa Pandowoharjo membutuhkan website sebagai sarana informasi, komunikasi dan promosi.

- Website yang dibangun dapat digunakan untuk menyampaikan informasi kepada masyarakat, dan membantu dalam layanan kegiatan pemerintahan desa seperti keperluan surat keterangan dan surat pengantar.

- Website yang dibangun juga dapat digunakan sebagai media pengarsipan kegiatan desa.

Saran:

- Perlu sosialisasi kepada perangkat desa dan penduduk desa, agar website yang telah dibangun dapat digunakan dengan baik.

- Perlu dibentuk bagian tersendiri yang bertugas untuk mengelola website, sehingga informasi yang disampaikan selalu dapat diperbahrui.

\section{Ucapan Terima Kasih (Acknowledgement)}

Ucapan terimakasih ditujukan kepada Direktorat Onelitian dan Pengabdian kepada Masyarakat Universitas Tarumanagara Jakarta (DPPM Untar) yang telah memberikan dukungan dan pendanaan, sehingga dapat terselenggaranya kegiatan pengabdian kepada masyarakat ini.

\section{REFERENSI}

Kosasi S., (2015). Penerapan Rapid Application Development Dalam Sistem Perniagaan Elektronik Furniture Citec Journal, Vol. 2, No. 4, Agustus 2015 - Oktober 2015 
McLuhan, M., Mcluhan, M.A. and Lapham, L.H., (2001). Understanding media: The extensions of man. MIT press.

Pemerintahan Desa Pandowoharjo. (2015). Rencana Pembangunan Jangka Menengah Desa Pandowoharjo 2015-2020.

Setiawan, Ade., (2011). Rapid Application Development. Univesitas Gunadarma

Undang-Undang Republik Indonesia Nomor 6 Tahun 2014

https://www.joomla.org/

http://www.internetworldstats.com/stats.htm

http://www.internetworldstats.com/stats3.htm 